the heart is paced to the same rate at rest (Braunwald et al., 1967). This factor alone seems insufficient to account for the relatively low critical rate in spontaneous arrhythmia, and possibly diminished ventricular acceptance of diastolic volume load also plays a part, in keeping with the observation that patients with reduced myocardial compliance due to hypertrophic or obliterative cardiomyopathy tolerate arrhythmia badly (Goodwin, 1970). A correctly timed atrial contraction is probably particularly important in these circumstances; and, similarly in arrhythmia following myocardial infarction, the importance of the loss of active atrial transport has been stressed (Fluck et al., 1967).

Cases 1, 8, and 9 of our series, who had presystolic atria! contraction before conversion, seemed to benefit as much from cardioversion as the others (Table II), implying that their atrial transport was not a particular asset. The numbers, however, are too few for this finding to be of significance. Also it is not certain that the return of a $P$ wave to the electrocardiogram in these patients necessarily meant immediate restoration of a normal left atrial contraction, certainly this is not always the case (Braunwald, 1964; Logan et al., 1965; Ikram et al., 1968). Experimental work with electrical pacing of the heart at varying rates has suggested that the gain in terms of cardiac output from atrial as opposed to ventricular stimulation is slight, but tends to be greater at increasing rates and in the abnormal heart (Benchimol and Liggett, 1966).

Clearly the ability of the individual patient to withstand any fall in cardiac output due to arrhythmia will depend not only on its degree and duration but also on other factors, particularly the state of the coronary and cerebral circulations and the presence or absence of valvular or myocardial disease. Our first patient was able to sustain for several weeks, at the age of 15 , a tachycardia of a rapidity which would not be tolerated by those in older age groups or with significant primary cardiovascular lesions.

We thank Mrs. Barbara Lea and the staff of the E.C.G. department, Sister J. Davies and the staff of the cardiac-catheter theatre, and Sister A. Gannicliffe and the staff of the coronary intensive care unit of the Liverpool Regional Cardiac Centre. We are indebted to Dr. T. Deegan for help with the statistical calculations.
This work was supported in part by Research Grant No. 92 from the Medical Research Committee of the United Liverpool Hospitals.

\section{REFERENCES}

Benchimol, A., Elis, J. G., Dimond, E. G., and Wu Teh-Lu. (1965) American Heart fournal, 70, 775

Benchimol, A., and Liggett, M. S. (1966). Circulation, 33, 933.

Braunwald, E. (1964). American fournal of Medicine, 37, 665.

Braunwald, E., Sonnenblick, E. H., Ross, J., jun., Glick, G., and Epstein, S. E. (1967). Circulation Research, 20, Suppl. No. 1, p. 44.

Chapman, C. B., Fisher, J. N., and Sproule, B. J. (1960). Fournal of Clinical Investigation, 39, 1208.

Fluck, D. C., et al. (1967). British Heart fournal, 29, 170.

Friedberg, C. K. (1966). Disease of the Heart, 3rd edn., p. 556. Philadelphia, Saunders.

Goodwin, J. F. (1970). Lancet, 1, 731.

Graettinger, J. S., Carleton, R. A., and Muenster, J. J. (1964). Fournal of Clinical Investigation, 43, 2290.

Halmos, P. B., and Patterson, G. C. (1965). British Heart fournal, 27, 719.

Hamilton, W. F., Moore, J. W., Kinsman, J. M., and Spurling, R. G. (1932) American fournal of Physiology, 99, 534 .

American fournal of Physiology, 99, 534.
Ikram, H., Nixon, P. G. F., and Arcan, T. (1968). British Heart fournal, $30,80$.

Kahn, D. R., Wilson, W. S., Weber, W., and Sloan, H. (1964). Fournal of Thoracic and Cardiovascular Surgery, 48, 898.

Killip, T., and Baer, R. A. (1966). Fournal of Clinical Investigation, 45, 658. Logan, W. F. W. E., Rowlands, D. J., Howitt, G., and Holmes, A. M. (1965). Lancet, $2,471$.

Lown, B., Amarasingham, $R$, and Neuman, J. (1962). Fournal of the American Medical Association, 182, 548.

McDonald, L. (1965). In Symposium on Advanced Medicine, ed. N. Compston, p. 351 . London, Pitman Medical.

Morris, J. J., jun., Entman, M., North, W. C., Kong, Y., and McIntosh, H. (1965). Circulation, 31, 670

New York Heart Association, Inc. (1964). Discases of the Heart and Blood Vessels, Nomenclature and Criteria for Diagnosis, 6 edn., p. 112. Boston, Little, Brown.

Oram, S., Davies, J. P. H., Weinbren, I., Taggart, P., and Kitchen, L. D. (1963). Lancet, 2, 159.

Reale, A. (1965). Circulation, 32, 214.

Reeves, J. T., Grover, R. F., Blount, S. G., jun., and Filley, G. F. (1961) fournal of Applied Physiology, 16, 283.

Rodman, T., Pastor, B. H., and Figueroa, W. (1966). American fournal of Medicine, 41, 249.

Ross, J., jun., Linhart, J. W., and Braunwald, E. (1965). Circulation, 32, 549. Rushmer, R. F. (1959). American fournal of Physiology, 196, 745.

Saltin, B., and Stenberg, J. (1964). Fournal of Applied Physiology, 19, 833.

Scott, M. E., and Patterson, G. C. (1969). British Heart Fournal, 31, 87.

Seldinger, S. I. (1953). Acta Radiologica, 39, 368

Shapiro, W., and Klein, G. (1968). Circulation, 38, 1074.

Turner, J. R. B., and Towers, J. R. H. (1965). Lancet, 2, 612.

\title{
Effect of Trimethoprim-Sulphamethoxazole on Typhoid and Salmonella Carriers
}

\author{
J. BRODIE,* M.D., D.P.H., F.R.C.PATH. ; I. A. MACQUEEN, $†$ M.D., D.P.H., D.S.C.H.E. \\ D. LIVINGSTONE, $\ddagger$ L.R.C.P.\& S. (ED., GLASG.), D.I.H., D.P.H.
}

British Medical fournal, 1970, 3, 318-319

\begin{abstract}
Summary: Four chronic typhoid carriers from the Aberdeen typhoid outbreak of 1964 were treated with trimethoprim-sulphamethoxazole. The male carrier remained clear of infection following treatment but the three female carriers, all with gall bladder abnormalities, remained excretors. A convalescent typhoid excretor also remained clear of infection after treatment as well as two other salmonella carriers, one of whom has been a chronic carrier for 24 years.
\end{abstract}

\section{Introduction}

The Aberdeen typhoid outbreak of 1964 (Walker, 1965) left a legacy of six chronic carriers of Salmonella typhi phage type 34 despite attempts to use ampicillin and other antibiotics to

* Consultant-in-Charge, the Laboratory, City Hospital, Aberdeen.

₹ Medical Officer of Health, County of Kincardine. clear convalescent carriers (Russell, Sutherland, and Walker, 1966). Since then two of the elderly carriers have died from other causes.

With the advent of trimethoprim-sulphamethoxazole (Septrin) it was decided that this would be worthy of trial, since the strain of $S$. typhi involved showed in-vitro sensitivity to this combination of synergistically active agents. Some possible success of its use in typhoid fever in Africa has been recorded (Pugsley, Mwanje, Pearson, and Blowers, 1969). The opportunity was taken also to assess its effects on a convalescent typhoid excretor and two chronic salmonella carriers. We here record the details of the investigations made with the co-operation of the patients involved who had the purpose of the trial fully explained to them.

\section{Patients Studied and Results}

Case 1.-A man aged 55 had remained stool-positive for $S$. typhi phage type 34 since the Aberdeen typhoid outbreak in 1964. 
A daily Septrin dosage of two tablets twice daily was begun on 26 July, 1969 and continued until 25 August. Stool culture was positive on 6 June. All subsequent stool and urine specimens, totalling 19 of each up to and including 9 April, 1970, have been negative for $S$. typhi.

Case 2.-A woman aged 68 , consistently stool-positive with an occasional positive urine since 1964, was given a one-month course of two Septrin tablets twice daily. One week after cessation of treatment, during which both stool and urine cultures were negative, stools and urine again yielded S. typhi. After the stool-positive result of 22 January, 1970, a nine-week course of the same dosage of Septrin was started. Again, one week after cessation of the second course of treatment the stool and urine cultures yielded $S$. typhi and the patient continued to excrete the organism.

Case 3.-A woman aged 63 had yielded S. typhi from stools and an occasional urine specimen since 1964. A course of two tablets of Septrin three times daily was begun on 24 July, 1969, and on 28 July the dosage was reduced to two tablets twice daily for a further month. During the period of treatment the faeces and urine samoles failed to yield $S$. typhi. As with Case 2, however, S. typhi was recovered from the stool one week after treatment ceased. A further extended course, consisting of two tablets thrice daily for one month and immediately thereafter by two tablets twice daily for a further five weeks, was begun. Again during treatment all cultures were negative, but, even so, specimens taken one week after the end of treatment were positive for $S$. typhi and have since remained positive.

Case 4.-A woman aged 47 was a persistent $S$. typhi faecal excretor with an occasional positive urine since 1964. The first course of Septrin, two tablets twice daily, started on 4 July, 1969 and ended on 1 August. With this patient, however, intermittent excretion of $S$. typhi continued during treatment; indeed, the specimen of stool taken on the last day of treatment was positive. A more sustained course of Septrin was begun on 14 October, and two tablets were given twice daily until 15 December. During this course also intermittent excretion of $S$. typhi occurred, to be followed after 15 December by a persistent positivity of stools with intermittent positivity of urine cultures.

The strains of $S$. $t y p h i$ recovered from each patient were sensitive in vitro to Septrin before treatment. All isolations from the three women subsequent to treatment were also as sensitive in vitro to Septrin as they had been previous to treatment. The only information available which might explain the success of treatment in Case 1 and the failure in Cases 2-4 would seem to centre on the past clinical findings, which showed the man to have a normally functioning gall bladder whereas the women had gall bladder abnormalities. Oral cholecystograms had been done on all. One patient (Case 1) was examined on 6 August 1965, when a concentration of the medium was found in the gall bladder but no stones could be identified. On 27 April 1965 Case 2 was reported to be obviously obese with a gall bladder shadow which could be distinguished only with difficulty, and, though the gall bladder appeared to be concentrating, it was difficult to exclude the presence of stones. Case 3 had had an oral cholecystogram done on 23 April 1965 and was reported as showing no definite evidence of a functioning gall bladder. Finally, Case 4, whose oral cholecystogram was done on 11 August 1965 had a gall bladder which showed only a faint concentration of medium and which did not appear to contract after a fatty meal. A single laminated gall stone was present in the fundus of the gall bladder.

Case 5.-A man aged 29 was a convalescent carrier of $S$. typhi phage type $\mathrm{K}$. He had been in hospital abroad, having had dizziness for 10 days and diarrhoeae for two days. Treatment consisted of chloramphenicol $3 \mathrm{~g}$. daily from 13 to 27 January, 1970. Rose spots appeared on 14 January. Blood culture was positive on 11 and 13 January. Stool cultures yielded S. typhi on 12 and 14 January but were negative on 19 January, and continued to be negative until his discharge on 3 February. After return to his home in this region his stools were positive on 14 and 17 February. He was treated with Septrin, two tablets twice daily, from 18 February to 18 March. All subsequent specimens up to and including 9 April were negative.

Two further salmonella carriers have been successfully cleared by the use of Septrin.

Case 6.-A man aged 48 gave a long history of intermittent gastrointestinal upsets, but no specimens were submitted to the laboratory. During field epidemiological investigations of a small outbreak of $S$. enteritidis infections, information seemed to point to a common milk supply. Survey of the farm supplying the milk and of its employees revealed this man to be a $S$. enteritidis carrier. His stools yielded the organism on 1, 8, and $28 \mathrm{July}, 1968$. In view of his occupation on the dairy farm, a short course of two Septrin tablets twice daily for seven days was given. Since then and up to 23 October his stools had been negative bacteriologically.

Case 7.-A man aged 51 first suffered from S. saint panl infection in November 1946, and had remained a persistent carrier since. He was given two Septrin tablets twice daily for five weeks starting from 16 October, 1969. Apart from one positive stool on 27 October, his stool cultures have since been consistently negative.

\section{Conclusion}

Treatment of typhoid and salmonella carriers with Septrin seems to indicate that this may be successful in clearing them from infection provided they have no gall bladder dysfunction. The results of this small trial may encourage others to assess the effects of the combined antibacterial action of trimethoprim and sulphamethoxazole in salmonella carriage and infection.

We wish to thank all doctors, health visitors, laboratory technicians, and others who gave willing assistance in these investiga-
tions.

\section{REFERENCES}

Pugsley, D. J., Mwanje, L., Pearson, C., and Blowers, R. (1969). Postgraduate Medical fournal, 45, November Suppl., p. 95.

Russell, E. M., Sutherland, A., and Walker, W. (1966). British Medical fournal, $2,555$.

Walker, W. (1965). Scottish Medical fournal, 10, 466. 